\title{
Lack of association between the connexin 37 C1019T gene polymorphism and coronary artery disease in a Chinese population: Meta-analysis of 2,206 subjects
}

\author{
YAN-YAN LI, YUN QIAN and CHUAN-WEI ZHOU \\ Department of Geriatrics, First Affiliated Hospital of Nanjing Medical University, Nanjing, Jiangsu 210029, P.R. China
}

Received January 7, 2013; Accepted March 6, 2013

DOI: $10.3892 /$ br. 2013.90

\begin{abstract}
The connexin 37 (Cx37) C1019T gene polymorphism has been suggested to be correlated with increased coronary artery disease (CAD) risk, but research results remain inconsistent. To explore the relationship between the Cx37 C1019T gene polymorphism and CAD in a Chinese population, the current meta-analysis of 6 individual studies involving 1,244 CAD patients and 962 controls was conducted. The pooled odds ratios (ORs) as well as the corresponding $95 \%$ confidence intervals (CIs) were estimated using a random- or fixed-effect model. No significant association was found between $C x 37$ C1019T gene polymorphism and CAD in the Chinese population under the allelic $(\mathrm{OR}=0.96 ; 95 \% \mathrm{CI}=0.59-1.56, \mathrm{P}=0.87)$, recessive $(\mathrm{OR}=0.77,95 \% \mathrm{CI}=0.28-2.08, \mathrm{P}=0.60)$, dominant $(\mathrm{OR}=0.990$, $95 \% \mathrm{CI}=0.773-1.266, \mathrm{P}=0.934)$, additive $(\mathrm{OR}=1.000,95 \%$ $\mathrm{CI}=0.736-1.359, \mathrm{P}=1.000)$, homozygous $(\mathrm{OR}=1.062,95 \%$ $\mathrm{CI}=0.598-1.887, \mathrm{P}=0.836)$ or heterozygous $(\mathrm{OR}=1.017,95 \%$ $\mathrm{CI}=0.802-1.291, \mathrm{P}=0.888)$ genetic models. $C x 37 \mathrm{C} 1019 \mathrm{~T}$ gene polymorphism was not suggested to be associated with CAD susceptibility in the Chinese population. In conclusion, no association was found between $C x 37 \mathrm{C} 1019 \mathrm{~T}$ gene polymorphism and CAD in the Chinese population.
\end{abstract}

\section{Introduction}

Coronary artery disease (CAD), a frequently encountered illness, poses a public health concern. CAD is considered to be a polygenic illness resulting from both environmental and hereditary factors (1). Genomic research is regarded as one of the four epoch-making revolutions and has become a study hotspot in exploring CAD pathogenesis from the molecular hereditary perspective (2).

Correspondence to: Dr Yan-Yan Li, Department of Geriatrics, First Affiliated Hospital of Nanjing Medical University, No. 300 Guangzhou Road, Nanjing, Jiangsu 210029, P.R. China

E-mail: lyynjmu123@126.com

Key words: connexin 37, C1019T gene polymorphism, mutation, coronary artery disease, Chinese, mutation
Connexin 37 (Cx37), a gap junction protein expressed in vascular endothelial cells, regulates and controls the growth, proliferation, senium, and regeneration of the vascular endothelium by mediating the signal transduction pathway between smooth muscle and endothelial cells (3). In 2009, Derouette et al found $C \times 37$ gene knockout mice to have the tendency to develop endarterium atheromatous plaques, suggesting that $C x 37$ is involved in the generation and progression of atherosclerosis as a protective landmark in the plaque formation process following endothelial injury (4). Thus, $C \times 37$ affects the development and progression of CAD and myocardial infarction (MI).

The Cx37 gene, located in 1p35.1, spans $2.727 \mathrm{~kb}$ and contains two exons and one intron encoding 333 amino acids (5). The variation of thymine ( $\mathrm{T}$ base) substituting for cytosine ( $\mathrm{C}$ base) in the 1,019th base of the Cx37 gene contributes to the supplantation of proline by serine in the 319 th base of the corresponding amino acid sequence. This rs1764391 mutation affects the tertiary structure formation of the gap junction protein. Moreover, the altered amino acid transforms the phosphorylation locus and further affects protein synthesis, transport, fabrication and signal transduction. Therefore, the function of vascular endothelial cells is affected to different extents, thus contributing to individual differences in CAD susceptibility (6).

Results also differed among the studies carried out in China. Zhang et al reported the $\mathrm{T}$ allele to be the hereditary risk factor for CAD (9). In contrast with Zhang's work, Han et al found that the $\mathrm{C}$ allele was probably correlated with CAD occurrence in the Chinese northern Han population (10). However, Zhang et al observed no association between CX37 C1019T gene polymorphism and CAD (11).

Considering the results of controversial studies on $C \times 37$ C1019T gene polymorphism and CAD, the present metaanalysis involving 2,206 subjects was conducted to deduce a reasonable conclusion on the association between $C x 37 \mathrm{C1019T}$ gene polymorphism and CAD in the Chinese population.

\section{Materials and methods}

Publication search and inclusion criteria. Selected studies published between 2001 and 2010 were obtained using the MeSH terms 'coronary artery disease' or 'coronary heart disease', 'polymorphism', 'connexin 37', 'gene,' and 'Chinese' 
in searching the electronic databases of PubMed, Embase, and Web of Science, as well as the China Biological Medicine Database and the China National Knowledge Infrastructure (last research updated on November 20, 2012).

The relevant publications were required to meet the following inclusion criteria: i) evaluation of Cx37 C1019T gene polymorphism and CAD in the Chinese population and ii) CAD diagnosis based on the examination results of coronary arteriography, clinical symptoms with electrocardiogram, echocardiography, treadmill exercise test, and myocardial perfusion imaging in emission computed tomography.

Data extraction. The data were extracted using a standard protocol. In the present meta-analysis, studies considered to be repeated publications, studies violating the inclusion criteria, or research providing little information were excluded. If the same data appeared in different manuscripts, only one study result was used. The drawn data comprised the following items: the first author's name, publication year, region, number of genotypes, genotyping method, study design, matching criteria, and total number of cases and controls.

Statistical analysis. The allelic (distribution of $\mathrm{T}$ allelic frequency of $C x 37$ C1019T gene polymorphism), recessive (TT vs. CC + CT), dominant (CC vs. CT + TT), additive ( $\mathrm{T}$ vs $\mathrm{C}$ ), homozygous (TT vs. CC), and heterozygous (CT vs. CC) genetic models were used. An odds ratio (OR) corresponding to a $95 \%$ confidence interval (CI) was used to compare the association of Cx37 C1019T and CAD. The Chi-square-based Q-test was applied to determine heterogeneity among studies (significance was set at the $\mathrm{P}<0.05$ level) (12). The variation attributed to heterogeneity was assessed by calculating the inconsistency index $\mathrm{I}^{2}$. As there was significant heterogeneity for all of the genetic models, the random-effect model (DerSimonian and Laird method) was applied for the above-mentioned models (13). The fixed-effect model was not used (the Mantel-Haenszel method) in the current meta-analysis (14). The pooled OR was determined by the $\mathrm{Z}$ test, and significance was set at $\mathrm{P}<0.05$.

The Hardy-Weinberg equilibrium (HWE) was assessed by Fisher's exact test, and significance was set as $\mathrm{P}<0.05$. The funnel plot was adopted to assess potential publication bias. The funnel plot asymmetry on the natural logarithm scale of the OR was assessed by Egger's linear regression test (significance was set at the $\mathrm{P}<0.05$ level) (15). Stata 11.0 software (StataCorp, College Station, TX, USA) was used for statistical analysis.

\section{Results}

Studies and populations. A total of 17 publications were derived from the literature search, from which 6 complied with the research inclusion criteria. Of the 11 excluded studies, 2 were published repeatedly, 2 were reviews, 3 were unassociated with Cx37 C1019T gene polymorphism, and 3 had foreign subjects. One study was excluded for deviating from HWE. Data were collected from a total of 1,244 CAD patients and 962 controls of the Han ethnicity (Table I) (9-11,16-18). The studies were conducted in 6 investigated regions: Taiwan, Zhejiang, Liaoning, Anhui, Shanxi and Guangdong.

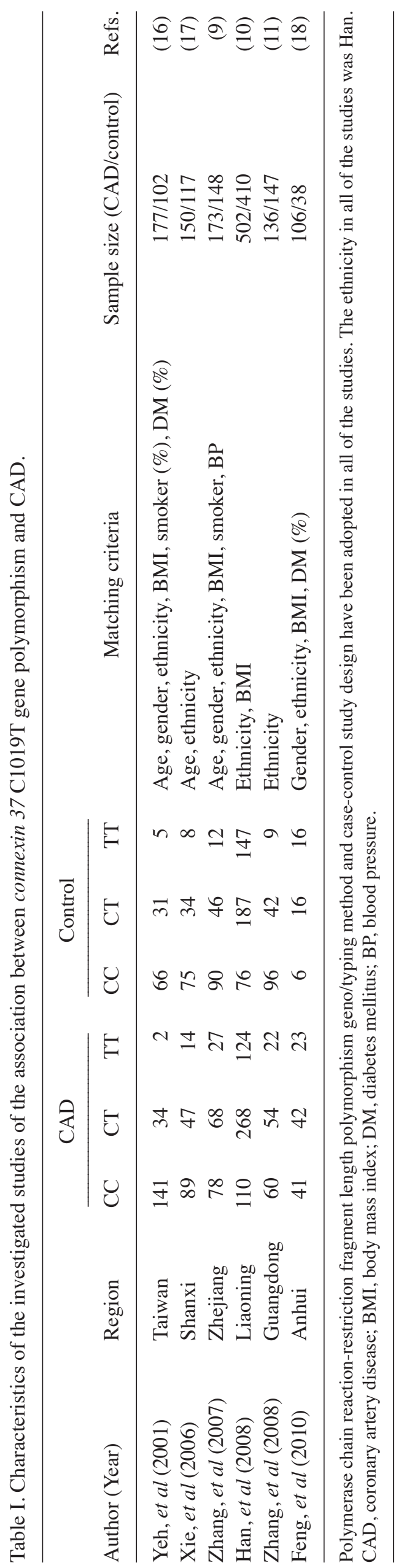




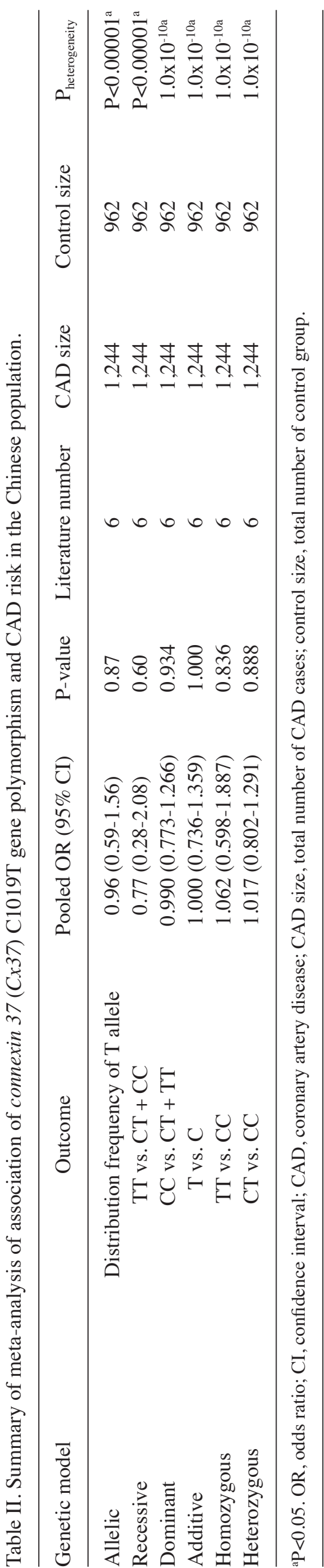

Combined analyses. No significant association was observed between Cx37 C1019T gene polymorphism and CAD in the Chinese population under the allelic $(\mathrm{OR}=0.96,95 \%$ $\mathrm{CI}=0.59-1.56, \mathrm{P}=0.87, \mathrm{P}_{\text {heterogeneity }}<0.00001, \mathrm{I}^{2}=91.1 \%$ ); recessive $\left(\mathrm{OR}=0.77,95 \% \mathrm{CI}=0.28-2.08, \mathrm{P}=0.60, \mathrm{P}_{\text {heterogeneity }}<0.00001\right.$, $\left.\mathrm{I}^{2}=90.1 \%\right)$; dominant $(\mathrm{OR}=0.990,95 \% \mathrm{CI}=0.773-1.266$, $\left.\mathrm{P}=0.934, \mathrm{P}_{\text {heterogeneity }}=1.0 \times 10^{-10}, \mathrm{I}^{2}=84.7 \%\right)$; additive $(\mathrm{OR}=1.000$, 95\% CI $=0.736-1.359, \mathrm{P}=1.000, \mathrm{P}_{\text {heterogeneity }}=1.0 \times 10^{-10}$, $\left.\mathrm{I}^{2}=91.0 \%\right)$; homozygous $(\mathrm{OR}=1.062,95 \% \mathrm{CI}=0.598-1.887$, $\left.\mathrm{P}=0.836, \mathrm{P}_{\text {heterogeneity }}=1.0 \times 10^{-10}, \mathrm{I}^{2}=86.0 \%\right)$ and heterozygous genetic models $(\mathrm{OR}=1.017,95 \% \mathrm{CI}=0.802-1.291, \mathrm{P}=0.888$, $\mathrm{P}_{\text {heterogeneity }}=1.0 \times 10^{-10}, \mathrm{I}^{2}=77.9 \%$ ) (Table II, Figs. 1 and 2).

Bias diagnostics. The funnel plot and Egger's test were adopted to assess publication bias. No visual publication bias was found in the funnel plot (Fig. 3). The difference was not statistically significant in the Egger's test, suggesting low publication bias in this meta-analysis (allelic genetic model, $\mathrm{T}=1.36, \mathrm{P}=0.247$ ).

\section{Discussion}

In the present meta-analysis, $C x 37 \mathrm{C} 1019 \mathrm{~T}$ gene polymorphism was not found to be associated with CAD susceptibility under the allelic $(\mathrm{OR}=0.96)$, recessive $(\mathrm{OR}=0.77)$, dominant $(\mathrm{OR}=0.990)$, additive $(\mathrm{OR}=1.000)$, homozygous $(\mathrm{OR}=1.062)$, and heterozygous genetic models $(\mathrm{OR}=1.017)$.

Atherosclerosis refers to the chronic inflammation of the arterial wall. Endothelial dysfunction is crucial in the early stages of atherosclerosis (19). Cell-to-cell interactions are required to maintain endothelial cell integrity. The cell gap junction is an important channel for message exchange between cells (20). In 2006, Wong et al found that $C x 37$ knockout mononuclear phagocytes adhered to the endothelium more strongly than $C x 37$-deficient cells (21). This characteristic was associated with the adenosine triphosphate (ATP) release between cells. Extracellular ATP release reduced the normally expressed mononuclear phagocytes of $C x 37$. By contrast, $C x 37$ knockout and inhibition of the $C x 37$ semi-pathway decreased extracellular ATP release causing mononuclear phagocytes to adhere to the matrix. This condition suggests that the Cx37 semi-pathway releases ATP, consequently prohibiting monocyte adhesion. Alteration of the cell adhesion characteristic contributes to mononuclear phagocyte aggregation in the atherosclerotic plaque and accelerates atherosclerotic progression (22). Therefore, $C x 37$ plays an important role in maintaining the structural and functional integrity of the vascular endothelium, preventing thrombosis, and inhibiting foam cell generation, which are closely correlated with the suppression of atherosclerotic progression.

In 1998, Yeh et al noted that $C x 37$ existed in coronary artery endothelial cells through immunological detection with a $C x 37$ antibody (23). Moreover, the mutation of $C x 37$ C1019T was associated with carotid artery atherosclerosis, acute MI, and CAD $(16,24,25)$. No consensus exists on the relationship between Cx37 C1019T polymorphism and CAD. In 2001, Yeh et al found that the $\mathrm{C}$ allele of the $C X 37$ gene potentially plays a role in the manifestation of coronary atherosclerosis in Taiwan (16). In 2010, Feng et al reported a similar result in male subjects from Anhui Province, China (18). By 
Review: Connexin 37 gene polymorphism and coronary artery disease in Chinese population: a meta-analysis

Comparison: $\quad 01$ CA.D group versus control group

Outcome: $\quad 01$ Distribution of T allelic frequency of Connexin 37gene C1019T polymorphism

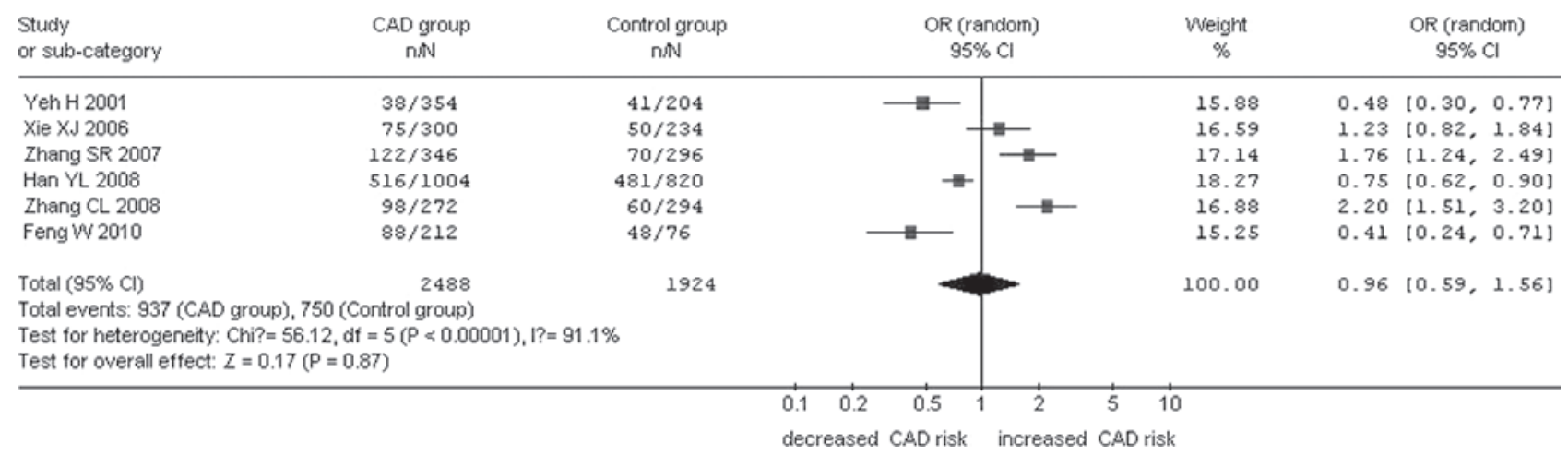

Figure 1. Forest plot of coronary artery disease (CAD) associated with connexin 37 C1019T gene polymorphism under an allelic genetic model (distribution frequency of T allelic of Cx37 C1019T gene).

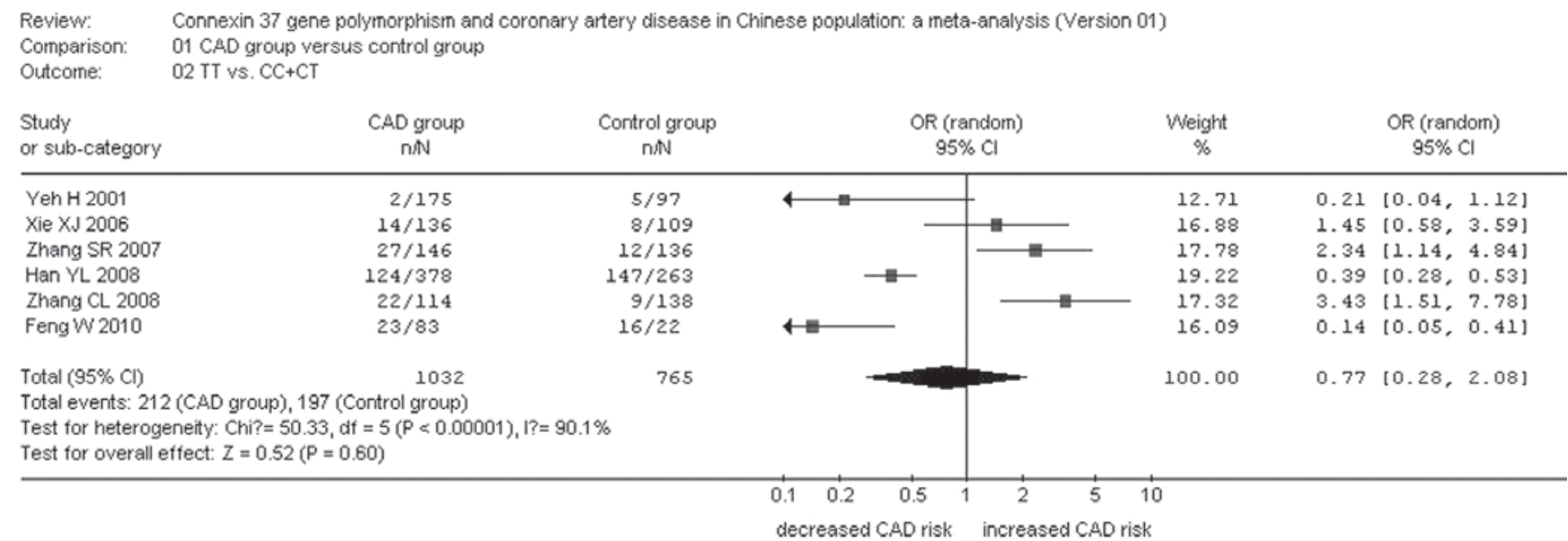

Figure 2. Forest plot of coronary artery disease (CAD) associated with connexin 37 C1019T gene polymorphism under a recessive genetic model (TT vs. CC + CT)

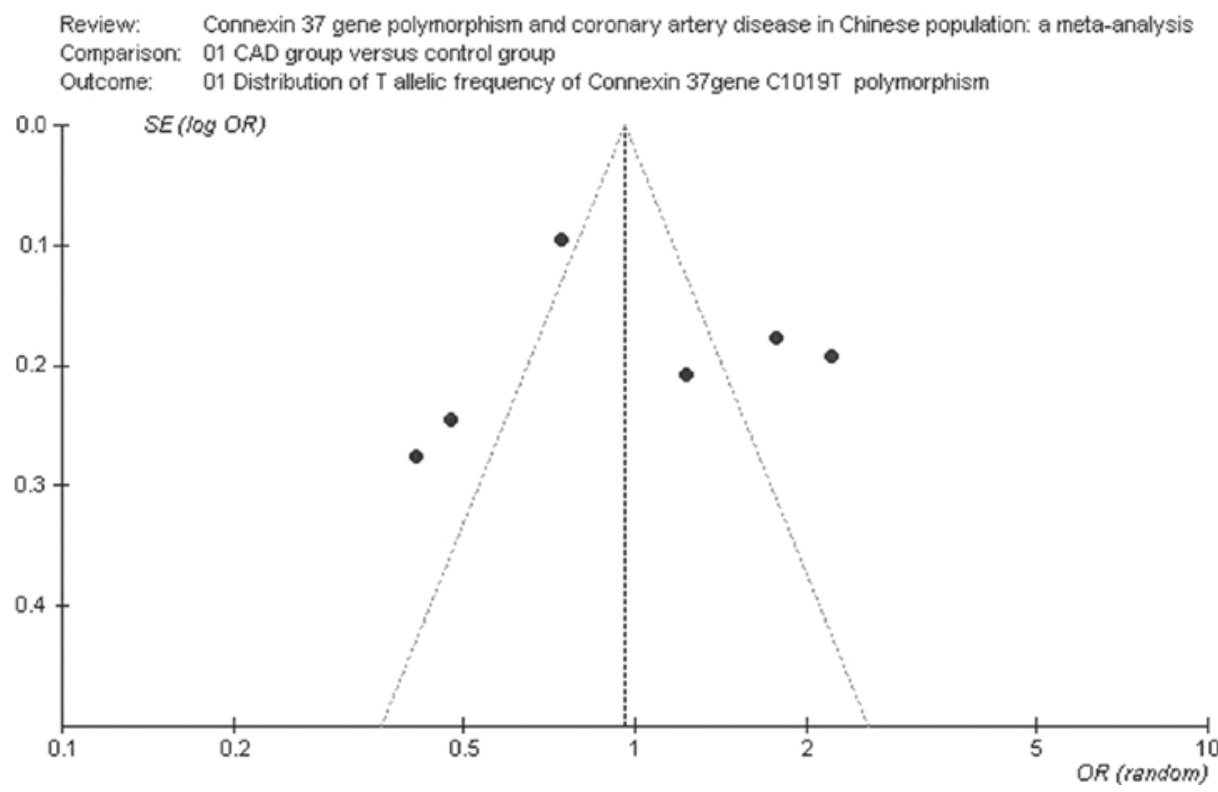

Figure 3. Funnel plot for studies of the association of coronary artery disease (CAD) and connexin 37 C1019T gene polymorphism under an allelic genetic model (distribution of $\mathrm{T}$ allelic frequency of connexin $37 \mathrm{C} 1019 \mathrm{~T}$ gene polymorphism). The horizontal and vertical axis correspond to the OR and confidence limits. OR, odds ratio; SE, standard error. 
contrast, Zhang SR et al and Zhang CL et al both reported different results showing that the $\mathrm{T}$ allele was a risk factor for CAD $(9,11)$.

The number of meta-analyses on gene polymorphism and CAD increases annually (26-28). However, no metaanalysis on the relationship between $C x 37 \mathrm{C} 1019 \mathrm{~T}$ gene polymorphism and CAD was retrieved. The current metaanalysis analyzed the independent studies on this subject comprehensively and quantitatively. The meta-analysis was used to analyze and summarize the collected research data using a statistical method and to provide a method to quantify the average effect to address the research question. The advantage of a meta-analysis involves its capacity to increase conclusion reliability and resolve inconsistency among study results by increasing the sample size. Therefore, the drawn conclusion should be more objective and reasonable than that of individual studies.

The present meta-analysis has a number of limitations. Sample non-uniformity in terms of gender, age and location existed among the individual studies. The case selection criteria and statistical methods differed among the independent studies. The illness phenotype was diverse. Large-scale studies on CAD and Cx37 C1019T were inadequate. Impact factors, such as diet and lifestyle, genetic background as well as pharmaceutical intervention, were considered distinct and require further investigation.

In conclusion, the present meta-analysis suggested no association between the $C x 37$ C1019T gene polymorphism and CAD susceptibility in the Chinese population. However, considering the above limitations, further studies are required to confirm these results.

\section{Acknowledgements}

This study was funded by the National Natural Science Foundation of China (NSFC 81100073 to Dr Yan-Yan Li), Priority Academic Program Development of Jiangsu Higher Education Institutions (PAPD) and Excellent Young and Middle-Aged Teachers Assistance Program of Nanjing Medical University for Dr Yan-yan Li. We would like to thank all our colleagues working in the Department of Geriatrics, the First Affiliated Hospital of Nanjing Medical University.

\section{References}

1. Li JJ: Inflammation: an important mechanism for different clinical entities of coronary artery diseases. Chin Med J (Engl) 118: 1817-1826, 2005

2. Hu D: Cardiology in new millennium: what will the 21st century bring. Chin Med J (Engl) 113: 3-4, 2000.

3. Yeh HI, Lai YJ, Chang HM, Ko YS, Severs NJ and Tsai CH: Multiple connexin expression in regenerating arterial endothelial gap junctions. Arterioscler Thromb Vasc Biol 20: 1753-1762, 2000 .

4. Derouette JP, Wong C, Burnier L, et al: Molecular role of Cx37 in advanced atherosclerosis: a micro-array study. Atherosclerosis 206: 69-76, 2009.

5. Van Camp G, Coucke P, Speleman F, Van Roy N, Beyer EC, Oostra BA and Willems PJ: The gene for human gap junction protein connexin37 (GJA4) maps to chromosome 1p35.1, in the vicinity of D1S195. Genomics 30: 402-403, 1995.
6. Cooper CD, Solan JL, Dolejsi MK and Lampe PD: Analysis of connexin phosphorylation sites. Methods 20: 196-204, 2000.

7. Listì F, Candore G, Lio D, et al: Association between C1019T polymorphism of connexin 37 and acute myocardial infarction: a study in patients from Sicily. Int J Cardiol 102: 269-271, 2005.

8. Wong CW, Christen T, Pfenniger A, James RW and Kwak BR: Do allelic variants of the connexin37 1019 gene polymorphism differentially predict for coronary artery disease and myocardial infarction? Atherosclerosis 191: 355-361, 2007.

9. Zhang SR, Xu LX, Zhang HQ, Gao QQ, Lin J and Huang WJ: The association between Connexin 37 gene C1019T polymorphism and coronary heart disease. Prev and Treat of Cardio-Cereb-Vasc Dis 7: 390-392, 2007.

10. Han Y, Xi S, Zhang X, Yan C, Yang Y and Kang J: Association of Connexin 37 gene polymorphisms with risk of coronary artery disease in northern Han Chinese. Cardiology 110: 260-265, 2008.

11. Zhang CL, Wang Q, Zheng L, et al: Association study between C1019T polymorphism in the connexin 37 gene and acute myocardial infarction in patients from Cantonese population of China. J Guangxi Med Univ 25: 844-847, 2008.

12. Cochran WG: The effectiveness of adjustment by subclassification in removing bias in observational studies. Biometrics 24: 295-313, 1968

13. DerSimonian R and Laird N: Meta-analysis in clinical trials. Control Clin Trials 7: 177-188, 1986.

14. Mantel N and Haenszel W: Statistical aspects of the analysis of data from retrospective studies of disease. J Natl Cancer Inst 22: 719-748, 1959.

15. Egger M, Davey Smith G, Schneider M and Minder C: Bias in meta-analysis detected by a simple, graphical test. BMJ 315: 629-634, 1997.

16. Yeh HI, Chou Y, Liu HF, Chang SC and Tsai $\mathrm{CH}$ : Connexin37 gene polymorphism and coronary artery disease in Taiwan. Int J Cardiol 81: 251-255, 2001.

17. Xie XJ, Guo WY, Li LS, Shu Q, Jiang WR, Zhang SZ and Li F: Association between Connexin 37 gene polymorphism and coronary heart disease. Chin Heart J 18: 539-541, 2006.

18. Feng W, Wang HJ and Wang Y: Relevance of Connexin 37 gene C1019T polymorphism and coronary heart disease in Han population in Anhui region. Chin J Cardiovasc Rehabil Med 19: 33-36, 2010.

19. Shimokawa H: Primary endothelial dysfunction: atherosclerosis. J Mol Cell Cardiol 31: 23-37, 1999.

20. Severs NJ, Rothery S, Dupont E, et al: Immunocytochemical analysis of connexin expression in the healthy and diseased cardiovascular system. Microsc Res Tech 52: 301-322, 2001.

21. Wong CW, Christen T, Roth I, et al: Connexin 37 protects against atherosclerosis by regulating monocyte adhesion. Nat Med 12: 950-954, 2006

22. Galkina E and Ley K: Vascular adhesion molecules in atherosclerosis. Arterioscler Thromb Vasc Biol 27: 2292-2301, 2007.

23. Yeh HI, Rothery S, Dupont E, Coppen SR and Severs NJ: Individual gap junction plaques contain multiple connexins in arterial endothelium. Circ Res 83: 1248-1263, 1998.

24. Collings A, Islam MS, Juonala M, et al: Associations between connexin 37 gene polymorphism and markers of subclinical atherosclerosis: the Cardiovascular Risk in Young Finns study. Atherosclerosis 195: 379-384, 2007.

25. Lanfear DE, Jones PG, Marsh S, Cresci S, Spertus JA and McLeod HL: Connexin37 (GJA4) genotype predicts survival after an acute coronary syndrome. Am Heart J 154: 561-566, 2007.

26. Wang F, Yang C, Song Y, Jiang Y and Ding Z: Periostin gene polymorphisms, protein levels and risk of incident coronary artery disease. Mol Biol Rep 39: 359-367, 2012.

27. Saedi M, Vaisi-Raygani A, Khaghani S, et al: Matrix metalloproteinas-9 functional promoter polymorphism $1562 \mathrm{C}>\mathrm{T}$ increased risk of early-onset coronary artery disease. Mol Biol Rep 39: 555-562, 2012.

28. Al-Daghri NM, Al-Attas OS, Alokail MS, Alkharfy KM and Hussain T: Adiponectin gene variants and the risk of coronary artery disease in patients with type 2 diabetes. Mol Biol Rep 38: 3703-3708, 2011 . 